\title{
Practical Investigations on SCR Based HVDC Power Transmission Systems
}

\author{
Ilampoornan.M.K ${ }^{1}$, and Prakash $\mathrm{S}^{2}$ \\ \{ ilampoornan.eee@bharathuniv.ac.in1; prakashacademics@gmail.com2\} \\ Professor, EEE Department, BIHER, Chennai,India ${ }^{1,2}$
}

\begin{abstract}
HVDC power transmission based converter uses both 6 pulse and 12 pulse schemes system. It is constructed mainly using the semiconductor devices for transfer of bulk amount of electric power, so that transmission cost reduces and efficiency increases. The AC power at the input of the HVDC transmission system is converted into high voltage dc for transmission. At the receiving end, this HVDC is converted back to high voltage AC using inverter technology. The conversion of AC input into dc output is done by SCR and IGBT.A high current and high power thyristor is employed in phase controlled rectifier circuit for converting AC input power into dc output power. This is used to provide variable voltage output DC and variable DC load current. The average output load voltage is controlled by varying the thyristor triggering angle. The IGBT based inverter is used with a set of LC filters to reduce output harmonics for load endurance protection and for elimination of various harmonics related problems. Here the degree of freedom is 2 because one phase voltage is reference and other two relative voltages are free to control. So the IGBT based 3 phase invetrter converts the HVDC into HVAC at the output. The output voltage is controlled by varying thyristor triggering angle. In the SCR based converter both 6 pulse and 12 pulse schemes are employed.
\end{abstract}

Keywords: HVDC,Converter,SCR,IGBT,Triggering Angle.

\section{Introduction}

HVDC transmission system predominantly use the converter for the converting AC to DC at the transmitting end also known as rectifier, it is converted back to DC at the receiving end also know as inverter. This converters are of two configuration either it is 6 pulse or 12-pulse arrangement, with valves connected in a three phase star- delta, star-star formation to the AC networks. The convertor has a reactor and dc capacitor for reactive power compensation. The AC filters are used for filtering harmonics. The converters are connected through the DC transmission lines which is either overhead line or submarine cable, when used in nearby locality back-to-back configuration is employed. Power electronics advanced technology contributes for the evolutiono of HVDC systems The fabrication and synthesis of most efficient semiconductor devices finds its application in the HVDC converter topologies. The fully controlled semiconductor devices available today for high-voltage high-power converters can be based on either thyristor or transistor technology. In this paper, the discussion is about rectifier side of the HVDC transmission system. Silicon controlled rectifier that is SCR is used for converting input AC to DC. This High voltage DC is given to the transmission line. In SCR based converter we use both 6 pulse and 12 pulse schemes. The basic block diagram of a HVDC transmission system is shown below in Figure 1. 


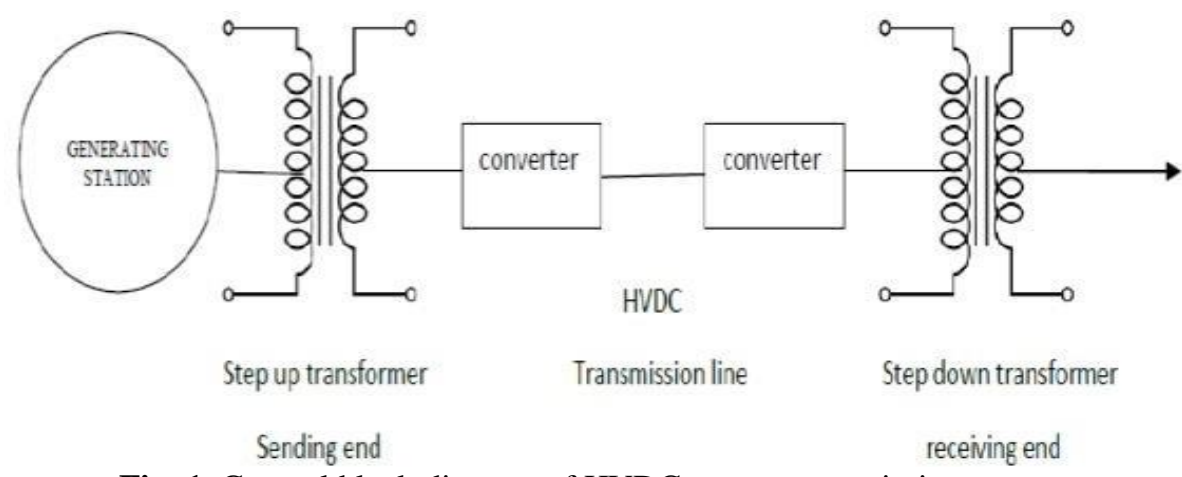

Fig. 1. General block diagram of HVDC power transmission system

To study the operation of SCR based converter, output is taken after the rectification for both 6 pulse and 12 pulse conditions. The basic diagram of SCR based converter is given below in Figure 2.

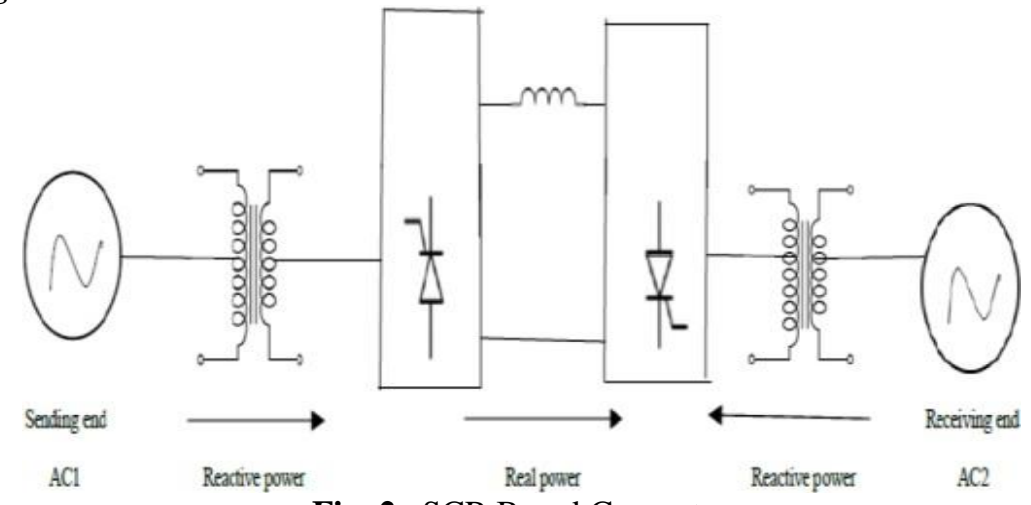

The rectification, i.e., the convertion of AC to HVDC is done here. which is then given to the transmission line.

\section{Six pulse operation}

The rectifier station consists of a full bridge 3 phase converter, one of three phase three winding transformer. In the AC side of the converter, higher order harmonics are generated. We use filters in both $\mathrm{AC}$ and $\mathrm{DC}$ side to reduce harmonic contents on input side and to reduce ripples in output DC voltage. PIC 4011 is used to provide gate pulse for thyristor. We use a single 6 SCR rectifier. The firing angle of rectifier can be varied from 0 to 120 degree and at each firing angle, DC voltage output can be taken from the rectifier.

\section{Twelve pulse operation}

The thyristor based full bridge three phase converters is used in rectifier station for voltage transformation two three phase three winding transformer is used. (ie, it has one three 
phase primary and two three phase secondary windings; one is star connected and the other is delta connected with phasors having 30 degree phase shift). The 12 pulse HVDC converter has odd current harmonics of order 11,13,23,25, even higher order are also generated on the alternating current side. Filters are installed to reduce the harmonics level to a level required by the network. The filters oin both $\mathrm{AC}$ and $\mathrm{DC}$ side are employed to reduce harmonic contents on input side and to reduce ripples in output DC voltage. PIC 4011 is used to provide gate pulse for thyristor. Two 6 SCR rectifiers whose firing angle can be varied from 0to30 degree and at each firing angle, DC voltage output can be taken from the rectifier.

\section{PWM(pulse width modulation)}

Pulse Width Modulation or PWM is a technique to get analogue output withdigital input. Using digital control, a square wave is created which can make a signal switched between on and off. The swiching frequency of the PWM has to be much higher than that would affect the load. The rate at which power supply switch can vary greatly according to load and application. The advantage of PWM is that power loss in the switching devices is very low. PWM has also been used in certain communication systems where its duty cycle is used to convey information over a communication channel.

\section{Equipment and methods}

The experiment was conducted on a HVDC transmission line analyzer which consists 4 parts. The first one is a generating station model in which 3 input voltages can be given in all 3 phases. The output of that is given to an SCR based rectifier station which converts the input AC into HVDC. In this paper,it is verified the HVDC output at both 6 pulse and 12 pulse operations. The remaining parts are simulated 650KV HVDC Transmission line and an IGBT based inverter. The Prototype of generating and rectifier stations are shown in the Figure 3. and Figure 4. Respectively. The Prototype of $650 \mathrm{kV}$ transmission line and invertor station are shown in the Figure 5. and Figure 6. Respectively. 


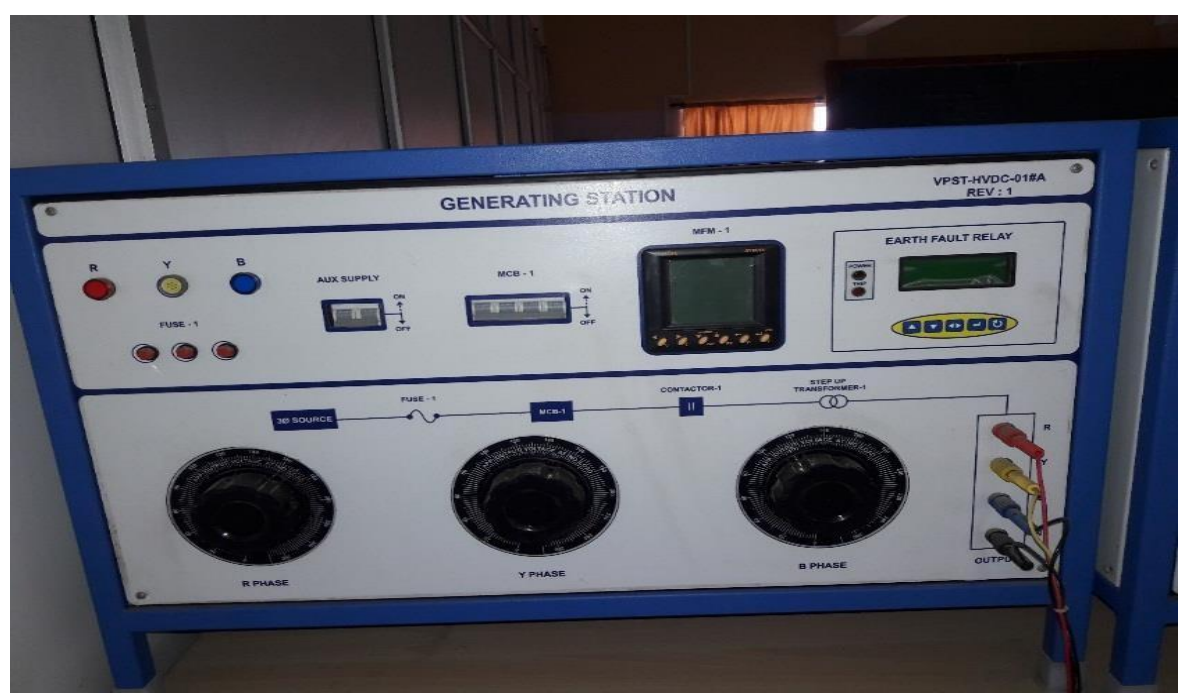

Fig. 3. Prototype of generating station

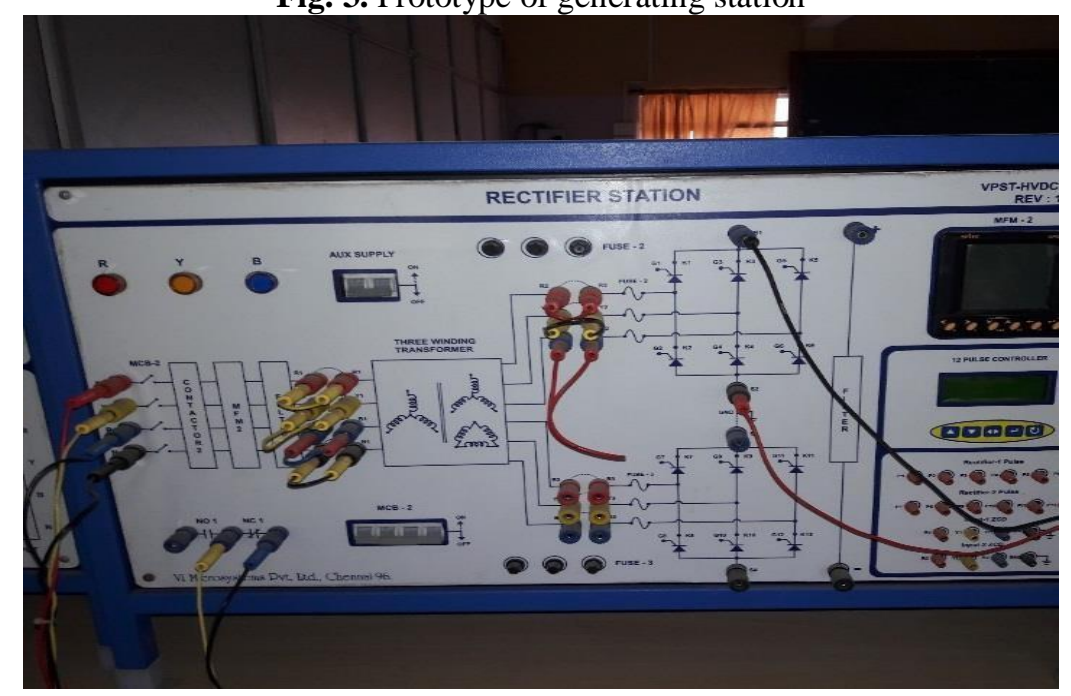

Fig. 4. Prototype of Rectifier station 


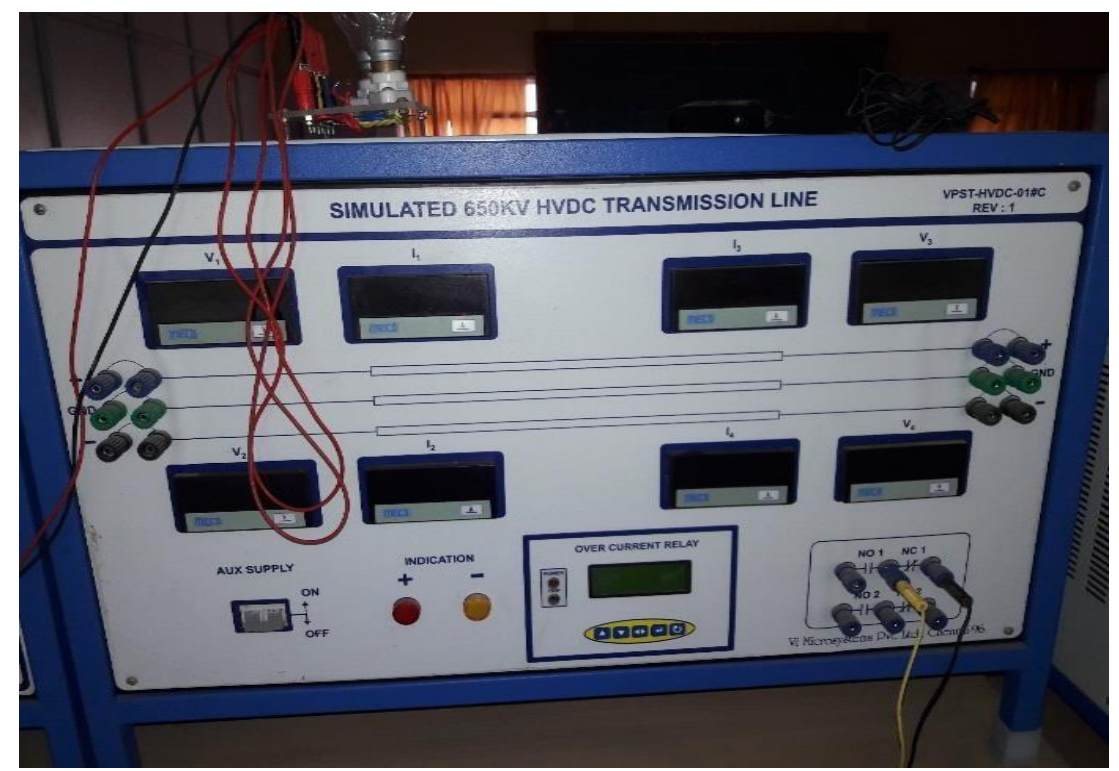

Fig. 5. Prototype of Simulated 650kV HVDC Transmission Line

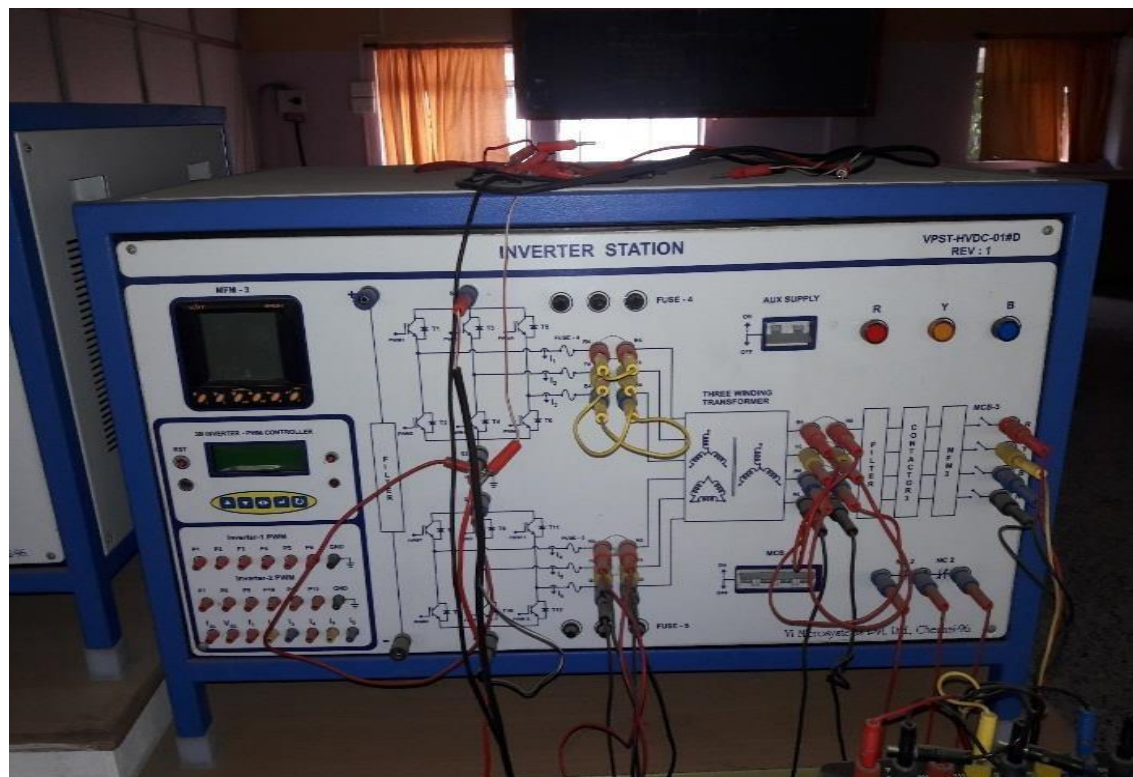

Fig. 6. Prototype of Inverter Station

The input voltage is kept constant at $110 \mathrm{KV}$ in each phase of the generating station and is given to SCR based converter(rectifier).The output is measured for this converter at firing angle from 0 to 120 on 6 pulse operation and 0 to 30 on 12 pulse operation. Then the comparison is made for the operation at 6 pulse and 12 pulse at firing angle 0 to $30 \mathrm{degree}$. 


\section{Results and discussions}

The 6 pulse operation is used to calculate the output of SCR based convertor at firing angle from 120 to 0 obtained values of DC voltage are tabulated in the Table.1 and graph of firing angle vs DC voltage is shown in Figure 7.

Table 1. Details of 6 pulse operation

\begin{tabular}{|c|c|}
\hline FIRING ANGLE & $\begin{array}{l}\text { MEASURED DC } \\
\text { VOLTAGE }\end{array}$ \\
\hline 120 & 148.5 \\
\hline 110 & 185 \\
\hline 100 & 220 \\
\hline 90 & 244 \\
\hline 75 & 254 \\
\hline 70 & 275 \\
\hline 65 & 264 \\
\hline 60 & 280 \\
\hline 55 & 202 \\
\hline 50 & 224 \\
\hline 45 & 193 \\
\hline 40 & 280 \\
\hline 35 & 264 \\
\hline 30 & 230 \\
\hline 25 & 236 \\
\hline 20 & 248 \\
\hline 15 & 254 \\
\hline 10 & 259 \\
\hline 5 & 263 \\
\hline 2 & 264 \\
\hline
\end{tabular}




\begin{tabular}{|l|l|}
\hline 1 & 264 \\
\hline 0 & 280 \\
\hline
\end{tabular}

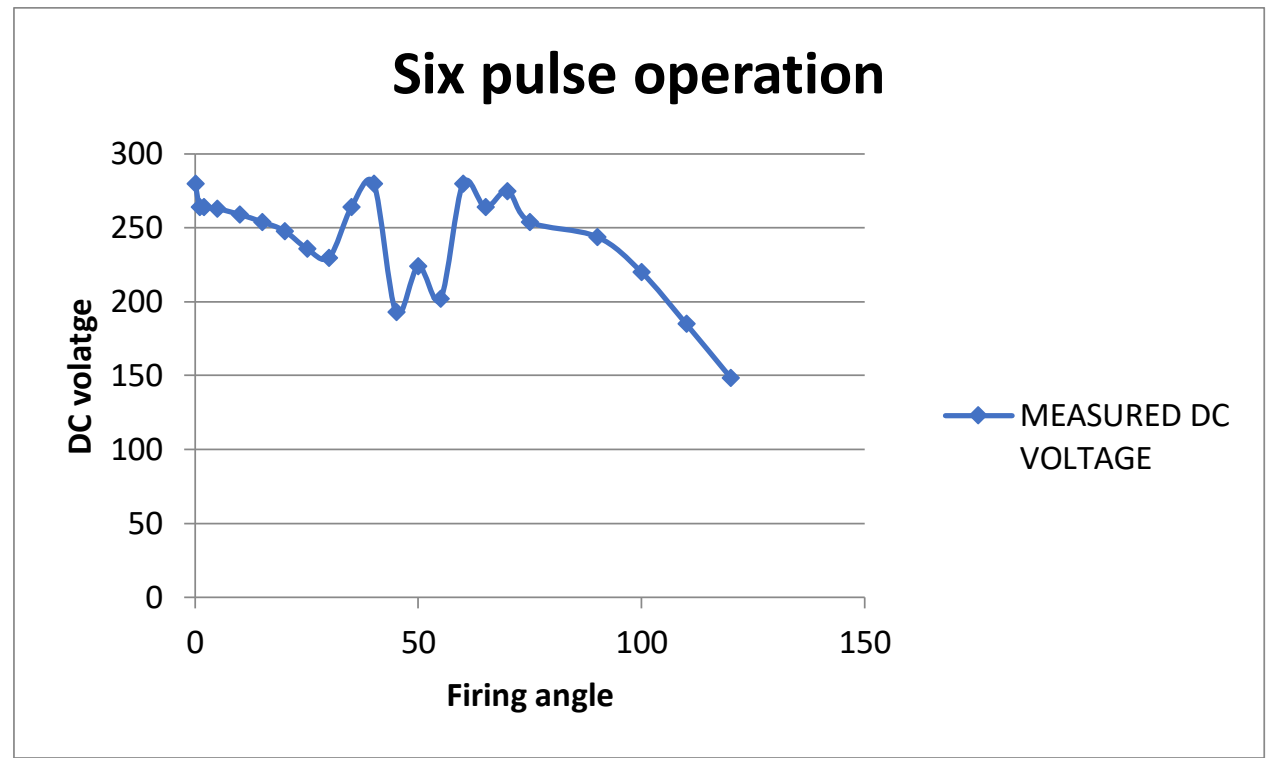

Fig. 7. Firing angle vs DC voltage(6 pulse)

Results for output DC voltage where firing angle is o to 30 degree is then taken for 12 pulse operation and shown in the Table 2. and graph of firing angle vs DC voltage is shown in Figure 8. The comparision between 6 pulse and 12 pulse is shown in the Table 3 . and corresponding graph is shown in Figure 9.

Table 2. Details of 12 pulse operation

\begin{tabular}{|l|l|}
\hline FIRING ANGLE & MEASURED DC VOLTAGE \\
\hline 30 & 436 \\
\hline 25 & 451 \\
\hline 20 & 466 \\
\hline 15 & 473 \\
\hline 10 & 475 \\
\hline 5 & 454 \\
\hline 1 & 425 \\
\hline
\end{tabular}




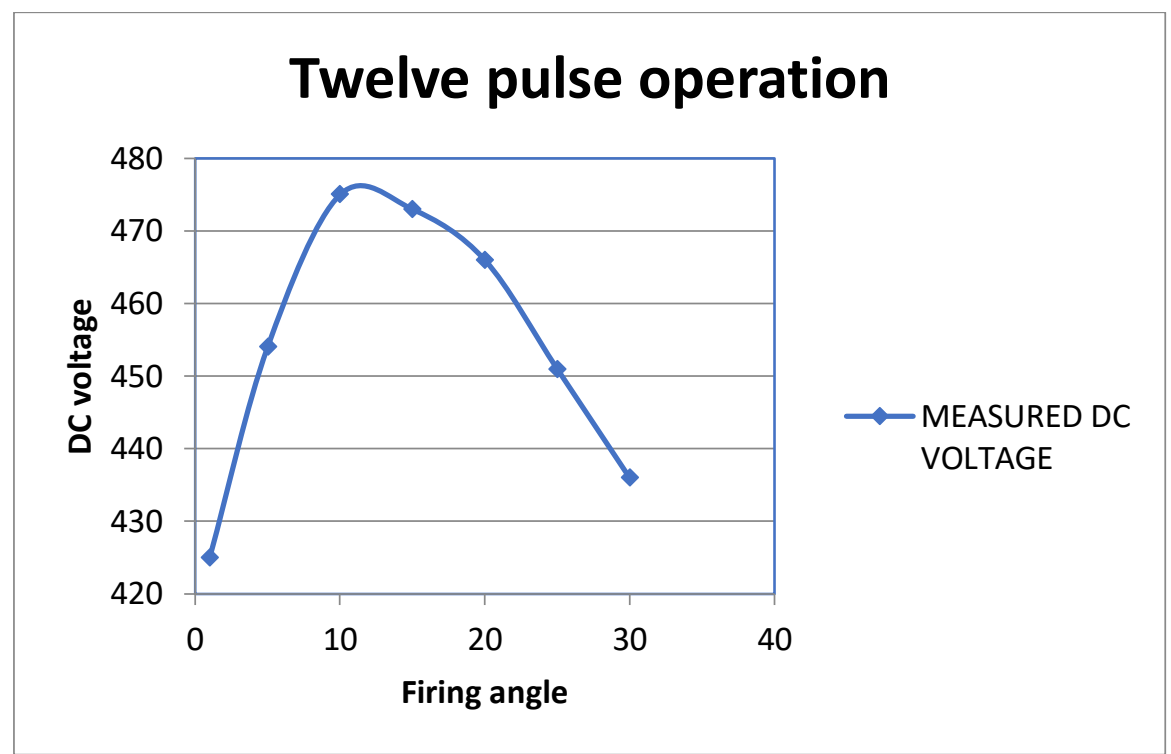

Fig. 8. Firing angle vs DC voltage(12 pulse)

Table 3. comparision of 12 and 6 pulse operation

\begin{tabular}{|l|l|l|}
\hline FIRING ANGLE & $\begin{array}{l}\text { DC VOLTAGE } \\
\text { ( 6 PULSE) }\end{array}$ & $\begin{array}{l}\text { DC VOLTAGE } \\
\text { (1 2 PULSE) }\end{array}$ \\
\hline 30 & 230 & 436 \\
\hline 25 & 236 & 451 \\
\hline 20 & 248 & 466 \\
\hline 15 & 254 & 473 \\
\hline 10 & 259 & 475 \\
\hline 5 & 263 & 454 \\
\hline 1 & 264 & 425 \\
\hline
\end{tabular}




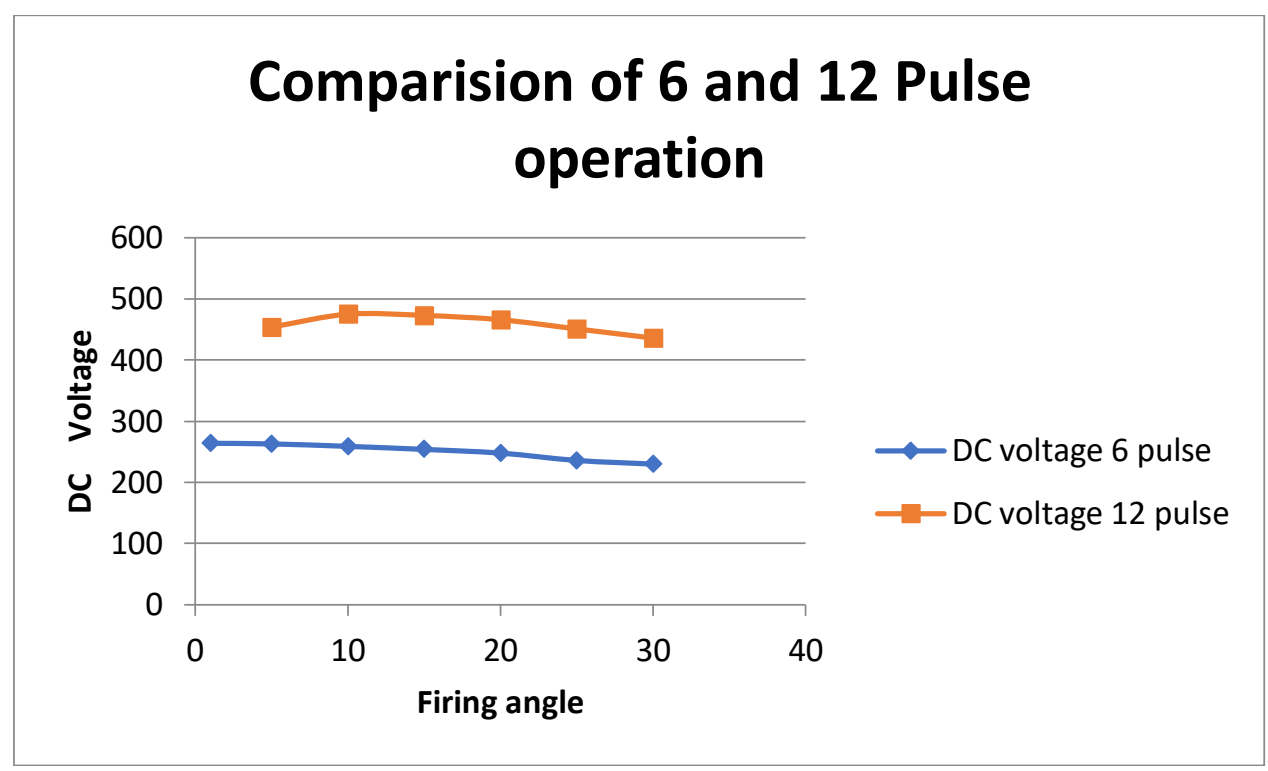

Fig. 9. Firing angle vs DC voltage( $6 \& 12$ pulse $)$

From this it is clear that at 12 pulse operation, voltage is almost doubled compared to 6 pulse operation. The output voltage is more steady and efficiency is more.

\section{Conclusion}

The output of the 6 pulse operation of the SCR based converter varies continuously and also produces lesser output voltage. Here losses are more and efficiency is less. In 12 pulse operation The output of SCR based converter is almost double of 6 pulse operation. Here losses are very less, output steadily varies according to firing angle and efficiency is more. The only advantage of 6 pulse operation over 12 pulse is that in 6 pulse operation, variation of firing angle from 0 to 120 degree is possible. But in 12 pulse, firing angle variation ranges from 0 to 30 degree. so in an SCR based converter 12 pulse operation is more preferable.

\section{References}

[1] Oluwafemi E. Oni, Kamati Mbangula, and Innocent E. Davidson. "A Review of LCC-HVDC and VSC-HVDC Technologies and Applications"

[2] Daniel Ludois and Giri Venkataramanan. "An Examination of AC/HVDC Power Circuits for Interconnecting Bulk Wind Generation with the ElectricGrid"

[3] Roberto Rudervall J.P. Charpentier Raghuveer Sharma ABB Power Systems World Bank ABB Financial Services Sweden United States Sweden. "High Voltage Direct Current (HVDC)Transmission Systems Technology ReviewPaper".

[4] Sharad Chandra Rajpoot,Prashant Singh Rajpoot,Kishan Gupta, Durga Sharma. "Analysis of Hvdc Power Transmission Line with Unique Power ControlRoom"

[5] International Research Journal of Engineering and Technology (IRJET) . Tanay Rastogi, Mohd. Tabish Siddiqui Prof. R.Sudha, Prof. K. Govardhan, VIT University, Vellore, Tamil Nadu. "Analysis 